Prof. Oldfield mentioned two investigations which show the present-day trend. In the first, attempts are being made to use rather complicated mathematical tools in describing the behaviour of a mazerunning animal at a point of choice; and in the second, an analysis is being made, again using quite advanced mathematics, of certain visual illusions first investigated by Ames in the United States. Both these investigations are of great theoretical interest in themselves. But in addition, as Prof. Oldfield pointed out, they throw light on human behaviour in its everyday setting or in the clinic.

Prof. Knight and Mr. Laird were concerned to show that some rather naïve methodological assumptions about human motivation have led to logical difficulties. They suggested other interpretative schemes free from these difficulties. Again, it was emphasized that theoretical considerations of this kind are directly related to practical and clinical problems.

Finally, the present writer pointed out the increasing demand for professional psychologists and the inadequacy of present training methods in Great Britain to meet that demand. He suggested that the most useful development would consist in the expan. sion of training at the graduate level. It was agreed, however, that professional training should not be allowed to develop at the expense of fundamental research, nor should it be dissociated from the consideration of theoretical problems. Recent developments suggest that a good deal of research which has itself no directly practical aim will be of relevance in the practical field.

So far as any trend in general psychology was revealed by the three papers, it was this : that the different schools and aims and methodologies of psychology are disappearing, and the field is becoming much more unitary than was the case during the first part of the present century. J. DREver

\section{BRITISH MEDICINE AND THE CONTINENT, $1600-1850$} NEW exhibition at the Wellcome Historical
Continent, 1600-1850"-presents some interesting
contrasts with the "Medicine in 1850" exhibition
which it has replaced. The latter exhibition dealt
with the medicine of Europe during a limited period,
and was, in effect, a cross-section of medical thought.
The new exhibition is designed to illustrate not so
much the state of medicine at various times in
different countries, as the fluctuating influence which
the medical and scientific thought of the European
Continent exercised on British medicine at different
times, and vice versa.

A limited aspect of this approach was well brought out by Prof. Edvard Gotfredsen, professor of the history of medicine in the University of Copenhagen, in his address at the official opening of the exhibition, which took place before a distinguished company on October 19. Prof. Gotfredsen chose to deal with the relations between British and Danish medicine in the seventeenth and eighteenth centuries. He pointed out that in the seventeenth century medicine was very international, and that, as Latin was the international language of learning, medical students were enabled to travel all over Europe to hear famous teachers. Danish students of medicine of that time were forced to go abroad for much of their education, since a full medical education could not then be obtained at the University of Copenhagen. Of the Danish medical students who later became famous, those who visited Great Britain included Caspar Bartholin the elder, who wrote an important work on medical education and recommended foreign travel. Caspar's son Erasmus visited London and Oxford in 1647, and his brother-in-law, Olaff Worm, stayed for a year and a half in England.

The impact of Harvey's doctrine of the circulation was important in Denmark, since the new theory was introduced into that country by Thomas Bartholin, who also had considerable influence in spreading it on the Continent. The Dane, Holger Jacobæus, who later became professor of anatomy at Copenhagen, left some interesting descriptions of his life in London and Oxford. Prof. Gotfredsen also described in some detail the difficulties which arose in the Royal Society in attempts to confirm Stensen's work on the effects of ligating the descending aorta. In the first half of the eighteenth century the travels of Danish students had become less extensive, and in the second half they practically ceased. This fact was due to the improvement of facilities for clinical instruction in Copenhagen.

Prof. Gotfredsen was introduced by Dr. E. Ashworth Underwood, director of the Wellcome Historical Medical Museum, and a vote of thanks to him for his address was proposed by' Sir Wilson Jameson.

The exhibition commences with the British and Continental background at the end of the sixteenth century. This extremely interesting period, which was the prologue to all that followed in the seventeenth century, was marked by the overwhelming importance of Paris, Montpellier and Padua. Of the English works of this period, mention should be made of the superb copy of the 1545 edition of the "Anatomy" of Geminus. Another rare work which is shown, and which itself had considerable influence on the Continent, was Mouffett's "Theatre of Insects", 1634. One of the rarest books shown in this exhibition is the first edition of "The byrth of mankynde"; this is the translation of the well-known book by Eucharius Roesslin. This first edition was published in 1540 and the copy shown is one of the very few perfect copies in existence.

It need scarcely be said that the section of the exhibition on Harvey contains fine first editions of his works. Harvey's influence on the medicine of the Continent is brought out by the published works of his supporters and of his opponents.

The rise of the Royal Society is shown in an interesting manner, as also are its connexions with the scientific men of the Continent. In the later sections Boerhaave and Haller are well represented by fine copies of their works and a number of relics. The influence of the Hunters dominates the second part of the period dealt with, and in this connexion many will be interested in the extra-illustrated edition of Jesse Foot's "Life of Hunter". This contains many original wash drawings which illustrate events in the life of John Hunter.

The later sections of the exhibition contain books and exhibits which are now classics of the late eighteenth and early nineteenth century developments of the sciences which form the fundamental basis of modern medicine. 